\title{
Oxidation of C.I. Acid Red 27 by Chloramine-T in perchloric acid medium: Spectrophotometric, kinetic and mechanistic approaches
}

\author{
Puttaswamy $^{\mathrm{a}, *}$, K.N. Vinod ${ }^{\mathrm{a}}$, K.N. Ninge Gowda ${ }^{\mathrm{b}}$ \\ ${ }^{a}$ Department of Chemistry, Central College Campus, Bangalore University, Bangalore 560 001, India \\ ${ }^{\mathrm{b}}$ Department of Apparel Technology and Management, Central College Campus, Bangalore University, Bangalore 560 001, India
}

Received 2 August 2007; received in revised form 14 November 2007; accepted 15 November 2007

Available online 23 November 2007

\begin{abstract}
The kinetics of the oxidation of the azo dye C.I. Acid Red 27 (Amaranth) by sodium $N$-chloro-p-toluenesulfonamide (Chloramine-T, [CAT]) in $\mathrm{HClO}_{4}$ medium were studied spectrophotometrically at $293 \mathrm{~K}$. The reaction rate shows first-order dependence on $[\mathrm{CAT}]_{0}$ and $[\mathrm{dye}]_{0}$ and an inverse-fractional order on $\left[\mathrm{HClO}_{4}\right]$. Activation parameters for the composite reaction and the reaction constants involved were computed. The stoichiometry of the reaction was found to be 1:1 and the oxidation products of the dye were identified as naphthalene and 1,2-naphthoquinone by GC-MS data. The observed results have been explained in terms of a mechanism and a relevant rate law has been deduced.

(c) 2007 Elsevier Ltd. All rights reserved.
\end{abstract}

Keywords: C.I. Acid Red 27; Chloramine-T; Oxidation kinetics; Acid medium

\section{Introduction}

Azo dyes contain one or more azo groups $(-\mathrm{N}=\mathrm{N}-)$ as the primary chromophore and they form the largest class of synthetic dyes. There are several monoazo dyes which are widely used as colorants in common foods and drugs [1]. The oxidation of azo dyes has attracted much attention in recent years [2]. The azo dye C.I. Acid Red 27 (Amaranth, trisodium 2hydroxy-1-(4-sulfanato-naphthalazo) naphthalene-3,6-disulfonate) is mainly used as a colorant in food, textile and paper industries [3]. Oxidation kinetic study of this dye is of greater significance in order to understand its mechanistic aspects in redox reactions. Although C.I. Acid Red 27 has been oxidized and decolorized by various oxidants, there seems to be no report in the literature on the kinetics of oxidation of this dye by positive halogen compounds. These facts obviate the need for us to undertake the present investigation.

\footnotetext{
* Corresponding author. Tel.: +91 80 22961340; fax: +91 8022961335 . E-mail address: pswamy_chem@yahoo.com (Puttaswamy).
}

The chemistry of aromatic sulfonyl haloamines, generally known as $N$-haloamines, has evinced considerable interest because they act as sources of both halonium cations and $\mathrm{N}$-anions which act as both bases and nucleophiles [4]. These are well known as mild oxidants and are known to interact with a range of functional groups in aqueous, partially aqueous, and non-aqueous media in the presence of an acid or alkali [4-6]. Sodium $N$-chloro- $p$-toluenesulfonamide, generally known as Chloramine-T (CAT), is a very important member of this class of $N$-haloamines. Chloramine-T is a source of positive halogen and this reagent has been exploited as an oxidant for a variety of substrates in both acidic and alkaline media [4-12]. However, literature survey reveals that only sporadic references are available on the kinetic aspects of oxidation of azo dyes by CAT [11]. Preliminary experimental results revealed that the oxidation of C.I. Acid Red 27 by CAT in alkaline medium is too slow to be measured but the reaction is facile in the presence of an acid. Hence, the present kinetic investigations have been carried out in acid medium.

In the light of the available information and in continuation of our research interest on the kinetic and mechanistic investigations of oxidation of various substrates in general and dyes 
in particular by CAT, the title reaction was undertaken. Consequently, in this communication we report on the detailed kinetics of C.I. Acid Red 27 oxidation by CAT in $\mathrm{HClO}_{4}$ medium at $293 \mathrm{~K}$ in order to: (i) elucidate the reaction mechanism, (ii) put forward appropriate rate law, (iii) characterize the oxidation products and (iv) develop an optimum condition for the facile oxidation of the substrate.

\section{Experimental}

\subsection{Materials}

Chloramine-T (Merck) was purified by the method of Morris et al. [12]. An aqueous solution of CAT was prepared, standardized iodometrically and stored in amber coloured bottle until further use to prevent its photochemical deterioration. The concentration of stock solutions was periodically determined. C.I. Acid Red 27 (Sigma) was used as-received and aqueous solution of the desired strength was prepared afresh each time. All other chemicals used were of analytical grade. Solvent isotope studies were made with $\mathrm{D}_{2} \mathrm{O}(99.4 \%$ purity) supplied by Bhabha Atomic Research Center, Mumbai, India. Doubly distilled water was used throughout the experiment.

Note: anhydrous and monohydrated perchloric acid can explode and slowly decompose at normal temperatures. Perchloric acid is extremely hazardous and can ignite or explode upon contact with organic material. The salts of perchloric acid are powerful oxidizers that are often used in explosive compositions.

\subsection{Kinetic procedure}

Kinetic measurements were carried out using an UV-vis spectrophotometer (Digital Spectrophotometer 166, Systronics, India). In the present study, the kinetic experiments were carried out between 288 and $308 \mathrm{~K}$. For this purpose, a Raagaa Ultra Cold Chamber with digital temperature control (India) was used. A constant temperature was maintained with an accuracy of $\pm 0.1{ }^{\circ} \mathrm{C}$. Detailed kinetic runs were performed under pseudo-first-order conditions of [oxidant $]_{0} \gg[\text { dye }]_{0}$ at constant concentration of $\mathrm{HClO}_{4}$ at $293 \mathrm{~K}$. Reactions were carried out in glass Stoppard Pyrex boiling tubes whose outer surfaces were coated black to eliminate any photochemical effects. The oxidant as well as requisite amounts of dye, $\mathrm{HClO}_{4}$ solutions and water (to keep the total volume constant for all runs) were taken in separate tubes and were thermostated for $30 \mathrm{~min}$ at $293 \mathrm{~K}$. The reaction was initiated by the rapid addition of a measured amount of oxidant to the stirred reaction mixture. Immediately, $4 \mathrm{ml}$ aliquot of the solution was pipetted into a cuvette placed in the spectrophotometer. Absorbance measurements were made at $521 \mathrm{~nm}$ ( $\lambda_{\max }$ of the dye) for nearly three half lives. The absorbance readings at $t=0$ and $t=t$ are $D_{0}$ and $D_{t}$. Plots of $\log D_{0} / D_{t}$ versus time were made to evaluate the pseudo-first-order rate constants $\left(k^{\prime}\right)$ which were found reproducible within $\pm 5 \%$. Regression analysis of the experimental data was carried out on an $f_{x}-100 \mathrm{~W}$ scientific calculator to evaluate the regression coefficient, $r$.

\section{Results and discussion}

\subsection{Stoichiometric and product analyses}

Varying ratios of CAT to C.I. Acid Red 27 dye in the presence of $1.0 \times 10^{-2} \mathrm{~mol} \mathrm{dm}^{-3} \mathrm{HClO}_{4}$ were equilibrated at $293 \mathrm{~K}$ for $48 \mathrm{~h}$. The unreacted CAT in the reaction mixture was determined by iodometric titration. The analysis showed that $1 \mathrm{~mol}$ of dye reacted with $1 \mathrm{~mol}$ of CAT and the observed reaction stoichiometry is represented as:

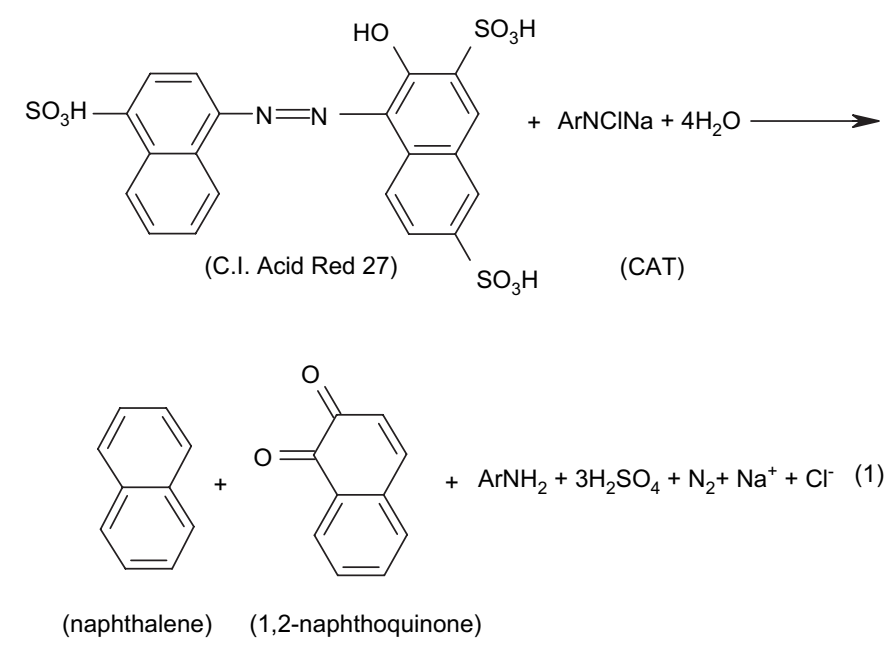

(Here, $\mathrm{Ar}=\mathrm{CH}_{3} \mathrm{C}_{6} \mathrm{H}_{4} \mathrm{SO}_{2}-$ )

The reaction mixture in the stoichiometric ratio under stirred condition was allowed to progress for $48 \mathrm{~h}$ at $293 \mathrm{~K}$. After completion of the reaction, products were neutralized with $\mathrm{NaOH}$ and extracted with ether. The organic products were subjected to spot tests and chromatographic analysis (TLC technique), which revealed the formation of oxidation products, namely naphthalene and 1,2-naphthoquinone. These oxidation products were separated by column chromatography and identified from their melting points: $80^{\circ} \mathrm{C}$ (lit. m.p. 78$80^{\circ} \mathrm{C}$ ) and $125^{\circ} \mathrm{C}$ (lit. m.p.124-126 ${ }^{\circ} \mathrm{C}$ ) for naphthalene and 1,2-naphthoquinone, respectively. These two products were further confirmed by $\mathrm{GC}-\mathrm{MS}$ analysis. GC-MS data were obtained on a 17A Shimadzu gas chromatograph with a QP-5050A Shimadzu mass spectrometer. The mass spectrum was obtained using the electron impact ionization technique. The mass spectra showed a molecular ion peak at 128 and $158 \mathrm{amu}$, clearly confirming naphthalene and 1,2-naphthaquinone, respectively (Figs. 1 and 2). All other peaks observed in GC-MS can be interpreted in accordance with the observed structure. Further, it was noticed that there was no reaction between naphthalene and 1,2-naphthoquinone with CAT under the present set of experimental conditions.

The reduction product of CAT, $p$-toluenesulfonamide (PTS or $\mathrm{ArNH}_{2}$ ), was extracted with ethyl acetate and detected by paper chromatography [13]. Benzyl alcohol saturated with 


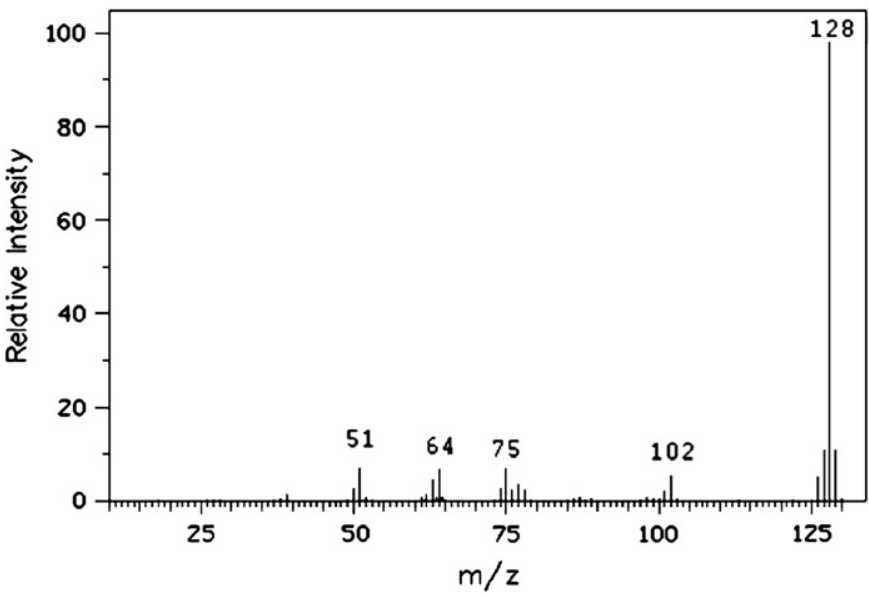

Fig. 1. GC-MS of naphthalene with its molecular ion peak at $128 \mathrm{amu}$.

water was used as the solvent with $0.5 \%$ vanillin in $1 \% \mathrm{HCl}$ solution (in ethanol) as spray reagent $\left(R_{f}=0.905\right)$. PTS was further confirmed by its melting point $138^{\circ} \mathrm{C}$ (lit. m.p. 138$\left.139^{\circ} \mathrm{C}\right)$ and $\mathrm{GC}-\mathrm{MS}$ analysis $(171 \mathrm{amu})$.

\subsection{Kinetic orders}

The oxidation of C.I. Acid Red 27 (henceforth abbreviated as dye) by CAT was kinetically investigated at different initial concentrations of the reactants in $\mathrm{HClO}_{4}$ medium at $293 \mathrm{~K}$. Under pseudo-first-order conditions of $[\text { dye }]_{0} \ll[\mathrm{CAT}]_{0}$ at constant $[\text { dye }]_{0},\left[\mathrm{HClO}_{4}\right]$ and temperature, plots of $\log ($ absorbance $)$ versus time were linear $(r>0.9901)$, indicating a first-order dependence of rate on $[d y e]_{0}$. The pseudo-first-order rate constants $\left(k^{\prime}\right)$ are listed in Table 1. Further, the values of $k^{\prime}$ remain unaltered with variation in $[\mathrm{dye}]_{0}$, confirming the first-order dependence of the rate on [dye $]_{0}$. Under the same experimental conditions, an increase in $[\mathrm{CAT}]_{0}$ increased the rate (Table 1). A plot of $\log k^{\prime}$ versus [CAT] $]_{0}$ was linear $(r=0.9970)$ having a slope equal to unity, indicating a first-order dependence of the reaction rate on $[\mathrm{CAT}]_{0}$. Further, a plot of $k^{\prime}$ versus

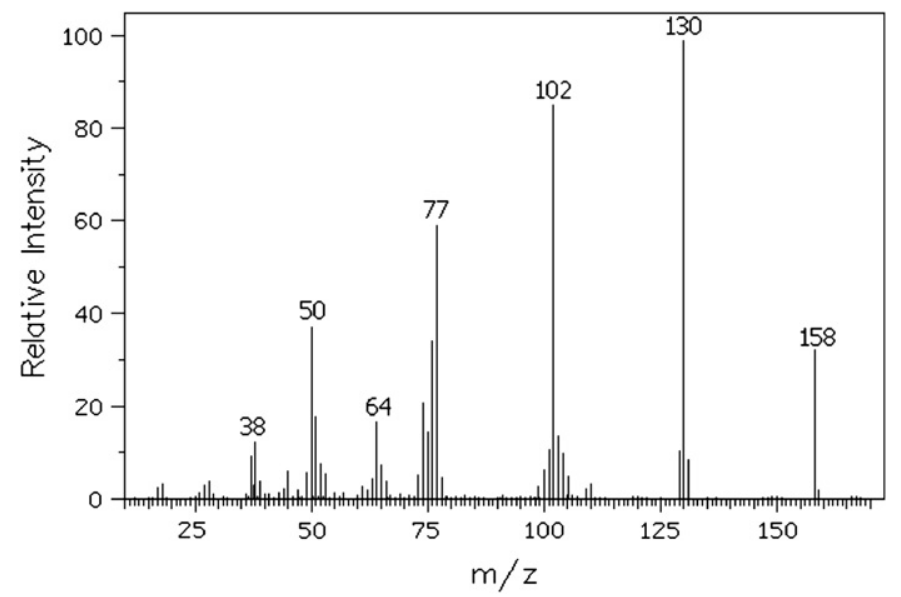

Fig. 2. GC-MS of 1,2-naphthoquinone with its molecular ion peak at $158 \mathrm{amu}$.
Table 1

Effect of varying CAT, C.I. Acid Red 27 and $\mathrm{HClO}_{4}$ concentrations on the reaction rate at $293 \mathrm{~K}$

\begin{tabular}{lllc}
\hline $\begin{array}{l}{[\mathrm{CAT}]_{0} \times 10^{3}} \\
\mathrm{~mol} \mathrm{dm}^{-3}\end{array}$ & $\begin{array}{l}{[\text { Dye }]_{\mathrm{o}} \times 10^{4}} \\
\mathrm{~mol} \mathrm{dm}\end{array}$ & $\begin{array}{l}{\left[\mathrm{HClO}_{4}\right] \times 10^{2}} \\
\mathrm{~mol} \mathrm{dm}^{-3}\end{array}$ & $k^{\prime} \times 10^{4} \mathrm{~s}^{-1}$ \\
\hline 0.2 & 1.0 & 1.0 & 1.83 \\
0.5 & 1.0 & 1.0 & 3.84 \\
1.0 & 1.0 & 1.0 & 6.58 \\
2.0 & 1.0 & 1.0 & 15.4 \\
6.0 & 1.0 & 1.0 & 40.8 \\
1.0 & 0.6 & 1.0 & 6.46 \\
1.0 & 0.8 & 1.0 & 6.38 \\
1.0 & 1.0 & 1.0 & 6.58 \\
1.0 & 1.2 & 1.0 & 6.75 \\
1.0 & 1.4 & 1.0 & 6.50 \\
1.0 & 1.0 & 0.2 & 10.1 \\
1.0 & 1.0 & 0.5 & 7.90 \\
1.0 & 1.0 & 1.0 & 6.58 \\
1.0 & 1.0 & 4.0 & 5.02 \\
1.0 & 1.0 & 8.0 & 3.83 \\
\hline
\end{tabular}

$[\mathrm{CAT}]_{0}$ was linear $(r=0.9983)$ passing through the origin, confirming the first-order dependence on $[\mathrm{CAT}]_{0}$.

At constant $[\mathrm{CAT}]_{0}$, $[\text { dye }]_{0}$, and temperature, the rate of the reaction decreased with increase in $\left[\mathrm{HClO}_{4}\right]_{0}$ (Table 1). A plot of $\log k^{\prime}$ versus $\log \left[\mathrm{HClO}_{4}\right]$ was linear with a negative slope of 0.58 , indicating a negative-fractional-order dependence on $\left[\mathrm{H}^{+}\right]$. Addition of $p$-toluenesulfonamide (PTS or $\mathrm{ArNH}_{2}$ ), reduction product of CAT $\left(1.0 \times 10^{-3}-8.0 \times 10^{-3} \mathrm{~mol} \mathrm{dm}^{-3}\right)$, to the reaction mixture did not affect the rate significantly. It indicates that PTS is not involved in any step prior to the rate-limiting step (rls) in the scheme proposed.

Addition of halide ions, $\mathrm{Cl}^{-}$or $\mathrm{Br}^{-}$, in the form of their sodium salts $\left(1.0 \times 10^{-3}-8.0 \times 10^{-3} \mathrm{~mol} \mathrm{dm}^{-3}\right)$ showed no pronounced effect on the rate. This indicates that the halide ions play no role in the reaction. The ionic strength of the reaction medium was varied from 0.1 to $0.3 \mathrm{~mol} \mathrm{dm}^{-3}$ with $\mathrm{NaClO}_{4}$ solution keeping other experimental conditions constant. It was found that addition of $\mathrm{NaClO}_{4}$ showed negligible effect on the reaction rate, indicating the involvement of nonionic species in the rate-limiting step. Hence no attempts were made to keep the ionic strength of the medium constant for kinetic runs.

The dielectric constant $(D)$ of the medium was varied by adding $\mathrm{MeOH}(0-30 \% \mathrm{v} / \mathrm{v})$ to the reaction mixture with all other experimental conditions being held constant. The rate decreased with increase in $\mathrm{MeOH}$ content (Table 2). A plot of $\log k^{\prime}$ versus $1 / D$ was linear $(r=0.9978)$ with a negative slope. It was further noticed that no reaction of the dielectric with the oxidant under the experimental conditions employed. The values of the dielectric constant of $\mathrm{CH}_{3} \mathrm{OH}-\mathrm{H}_{2} \mathrm{O}$ mixtures reported in the literature [14] were employed. As the oxidation of C.I. Acid Red 27 by CAT was retarded by $\left[\mathrm{H}^{+}\right]$, the solvent isotope effect was studied in $\mathrm{D}_{2} \mathrm{O}$ as the solvent medium. The reaction was further retarded with $k^{\prime}=4.49 \times 10^{-4} \mathrm{~s}^{-1}$ in $\mathrm{D}_{2} \mathrm{O}$ medium and $6.58 \times 10^{-4} \mathrm{~s}^{-1}$ in $\mathrm{H}_{2} \mathrm{O}$, leading to a solvent isotope effect, $k^{\prime}\left(\mathrm{H}_{2} \mathrm{O}\right)$ / $k^{\prime}\left(\mathrm{D}_{2} \mathrm{O}\right)=1.46$. 
Table 2

Effect of varying dielectric constant of the medium on the rate of reaction at $293 \mathrm{~K}$

\begin{tabular}{lll}
\hline$\% \mathrm{MeOH}(\mathrm{v} / \mathrm{v})$ & $D$ & $k^{\prime} \times 10^{4} \mathrm{~s}^{-1}$ \\
\hline 0 & 76.73 & 6.58 \\
5 & 74.50 & 6.50 \\
10 & 72.37 & 6.22 \\
20 & 67.48 & 5.45 \\
30 & 62.71 & 4.88 \\
\hline
\end{tabular}

$[\mathrm{CAT}]_{0}=1.0 \times 10^{-3} \mathrm{~mol} \mathrm{dm}^{-3} ; \quad[\text { dye }]_{0}=1.0 \times 10^{-4} \mathrm{~mol} \mathrm{dm}^{-3} ; \quad\left[\mathrm{HClO}_{4}\right]=$ $1.0 \times 10^{-2} \mathrm{~mol} \mathrm{dm}^{-3}$.

The effect of temperature on the reaction rate was studied by performing the kinetic runs in the range of $288-308 \mathrm{~K}$ (288, 293, 298, 303 and $308 \mathrm{~K})$, keeping other experimental conditions constant. From the linear Arrhenius plot of $\log k^{\prime}$ versus $1 / T(r=0.9930)$, values of activation parameters $\left(E_{\mathrm{a}}\right.$, $\Delta H^{\neq}, \Delta S^{\neq}, \Delta G^{\neq}$and $\log$ A) for the overall reaction were evaluated. These data are presented in Table 3. Addition of the reaction mixture to the acrylamide monomer did not initiate polymerization, indicating the absence of free radicals in the reaction mixture. Control experiments performed with solutions containing all the components of the reaction mixture except the oxidant and with the individual oxidant solutions were found to be negative.

\subsection{Reactive species of Chloramine-T}

Chloramine-T (ArNCINa) acts as a mild oxidant in both acidic and alkaline media. In general, CAT undergoes a twoelectron change in its reactions forming the reduction products, PTS and sodium chloride. The oxidation potential of CAT-PTS redox couple varies with $\mathrm{pH}$ of the medium $(1.139 \mathrm{~V}$ at $\mathrm{pH} 0.65,0.778 \mathrm{~V}$ at $\mathrm{pH} 7.0$ and $0.614 \mathrm{~V}$ at $\mathrm{pH}$ 9.7). Aqueous solutions of CAT behave as a strong electrolyte and depending on the $\mathrm{pH}$, CAT furnishes [12,15-17] different types of reactive species as follows [Eqs. (2-8)]:

$\mathrm{ArNClNa} \rightleftarrows \mathrm{ArNCl}^{-}+\mathrm{Na}^{+}$

$\mathrm{ArNCl}^{-}+\mathrm{H}^{+} \rightleftarrows \mathrm{ArNHCl}$

Table 3

Effect of varying temperature on the rate of reaction and activation parameters for the oxidation of C.I. Acid Red 27 by CAT in acid medium

\begin{tabular}{ll}
\hline Temperature $(\mathrm{K})$ & $k^{\prime} \times 10^{4} \mathrm{~s}^{-1}$ \\
\hline 288 & 4.36 \\
293 & 6.58 \\
298 & 8.61 \\
303 & 13.1 \\
308 & 16.0 \\
$E_{\mathrm{a}}\left(\mathrm{kJ} \mathrm{mol}^{-1}\right)$ & 47.8 \\
$\Delta H^{\neq}\left(\mathrm{kJ} \mathrm{mol}^{-1}\right)$ & 45.3 \\
$\Delta G^{\neq}\left(\mathrm{kJ} \mathrm{mol}^{-1}\right)$ & 90.3 \\
$\Delta S^{\neq}\left(\mathrm{J} \mathrm{K}^{-1} \mathrm{~mol}^{-1}\right)$ & -151 \\
$\log \mathrm{A}$ & 5.35 \\
\hline
\end{tabular}

$[\mathrm{CAT}]_{0}=1.0 \times 10^{-3} \mathrm{~mol} \mathrm{dm}^{-3} ; \quad[\text { dye }]_{0}=1.0 \times 10^{-4} \mathrm{~mol} \mathrm{dm}^{-3} ; \quad\left[\mathrm{HClO}_{4}\right]=$ $1.0 \times 10^{-2} \mathrm{~mol} \mathrm{dm}^{-3}$.

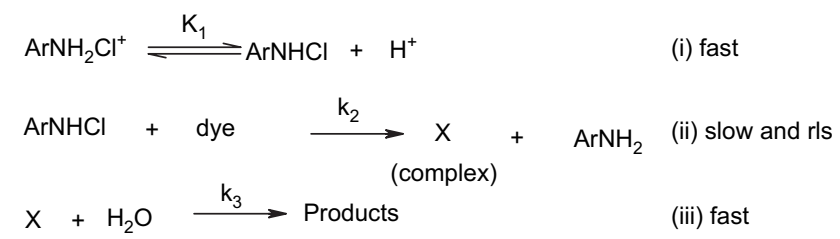

Scheme 1. A general probable scheme for the oxidation of C.I. Acid Red 27 by CAT in acid medium.

$2 \mathrm{ArNHCl} \rightleftarrows \mathrm{ArNH}_{2}+\mathrm{ArNCl}_{2}$

$\mathrm{ArNHCl}+\mathrm{H}_{2} \mathrm{O} \rightleftarrows \mathrm{ArNH}_{2}+\mathrm{HOCl}$

$\mathrm{ArNCl}_{2}+\mathrm{H}_{2} \mathrm{O} \rightleftarrows \mathrm{ArNHCl}+\mathrm{HOCl}$

$\mathrm{HOCl} \rightleftarrows \mathrm{H}^{+}+\mathrm{OCl}^{-}$

$\mathrm{HOCl}+\mathrm{H}^{+} \rightleftarrows \mathrm{H}_{2} \mathrm{OCl}^{+}$

Therefore, the possible oxidizing species in acidified CAT solutions are $\mathrm{ArNHCl}, \mathrm{ArNCl}_{2}, \mathrm{HOCl}$, and also perhaps $\mathrm{H}_{2} \mathrm{OCl}^{+}$. If $\mathrm{ArNCl}_{2}$ was to be the reactive species, then the rate law predicts a second-order dependence of rate on $[\mathrm{CAT}]_{0}$, which is contrary to the experimental observations. If $\mathrm{HOCl}$ is primarily involved, a first-order retardation of rate by adding $p$-toluenesulfonamide is expected. Since no such effect is noticed, $\mathrm{HOCl}$ can be ruled out as the oxidizing species. Hardy and Johnston [16], who have studied the $\mathrm{pH}$ dependent relative concentrations of the species present in acidified CAT solutions of comparable molarities, have shown that $\mathrm{ArNHCl}$ is the likely oxidizing species in acid medium. Hence, we suppose ArNHCl to be the most probable reactive oxidizing species for the oxidation of the dye by CAT in the present redox system. Further, formation of species of the type $\mathrm{ArNH}_{2} \mathrm{Cl}^{+}$has been reported $[18,19]$ with CAT and the protonation constant for the reaction

$\mathrm{ArNHCl}+\mathrm{H}^{+} \rightleftarrows \mathrm{ArNH}_{2} \mathrm{Cl}^{+}$

was found to be $1.02 \times 10^{2}$ at $25^{\circ} \mathrm{C}$.

\subsection{Reaction scheme}

In the present investigations, the retardation of rate by $\mathrm{H}^{+}$ ion indicates that the unprotonated oxidant $(\mathrm{ArNHCl})$ is the most active oxidizing species. In view of preceding discussion and the experimental facts, Scheme 1 is proposed to explain the reaction mechanism for the oxidation of C.I. Acid Red 27 by $\mathrm{CAT}$ in $\mathrm{HClO}_{4}$ medium.

In Scheme 1, X represents the complex intermediate species, the structure of which is defined in Scheme 2, where a detailed probable mechanistic interpretation of C.I. Acid Red 27 oxidation by CAT in acid medium is illustrated.

Dyes, such as C.I. Acid Red 27, containing hydroxy groups conjugated to azo group exhibit azo-hydrazone tautomerism as shown below: 


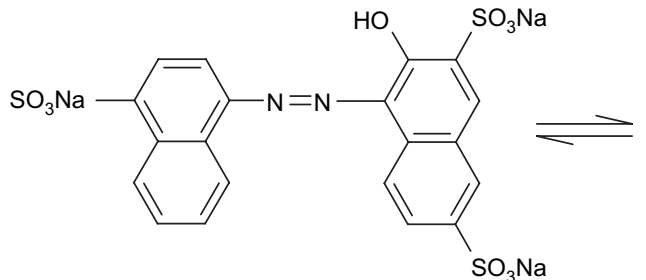

(Azo)

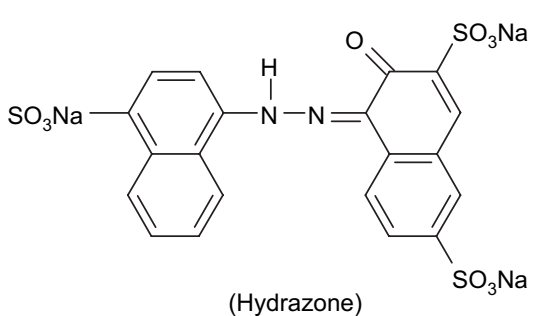

(Hydrazone)
In the present case, the azo form of the dye reacts with the conjugate acid of the oxidant to form the substrate-CAT complex (X) with the elimination of $\mathrm{ArNH}_{2}$. The complex (X) in acid medium undergoes protodesulfonation followed by hydrolysis and cleavage of azo bond to yield the ultimate products viz., naphthalene and 1,2-naphthoquinone as shown in Scheme 2.

\subsection{Deduction of rate law}

If the effective concentration of CAT is $[\mathrm{CAT}]_{t}$, then

$[\mathrm{CAT}]_{t}=\left[\mathrm{ArNH}_{2} \mathrm{Cl}^{+}\right]+[\mathrm{ArNHCl}]$

i) $\mathrm{ArNH}_{2} \mathrm{Cl}^{+} \rightleftharpoons \mathrm{ArNHCl}+\mathrm{H}^{+}$

ii) $\mathrm{ArNHCl}+\mathrm{HO}_{3} \mathrm{~S}$<smiles>Cc1ccc(N=Nc2c(O)c(S(=O)(=O)O)cc3cc(S(=O)(=O)O)ccc23)c2cc(O)ccc12</smiles>

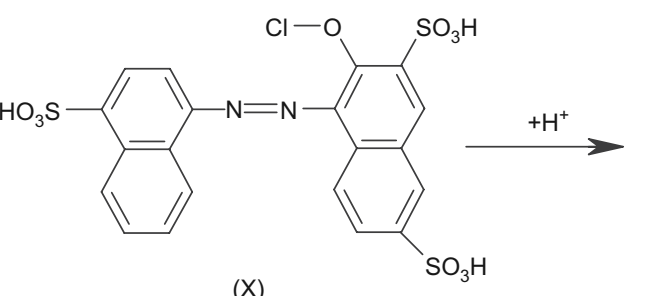

$(\mathrm{X})$
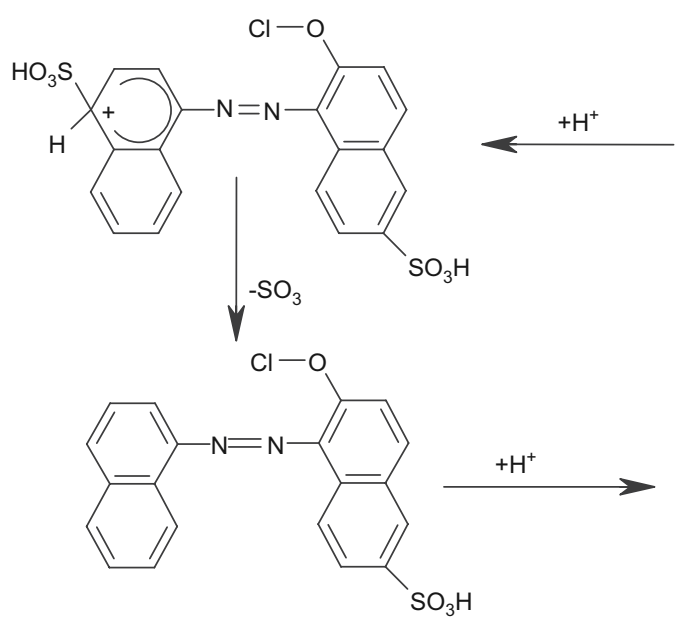

$(\mathrm{X})$<smiles>O=[N+]([O-])c1ccc(N=Nc2c(OCl)cc([R9](=O)(=O)O)c3cc(S(=O)(=O)O)ccc23)c2ccccc12</smiles>
$-\mathrm{SO}_{3}$<smiles>O=S(=O)(O)c1ccc2c(N=Nc3cccc4ccccc34)c(OCl)ccc2c1</smiles><smiles>CC(C)C(C)(C)C(=O)O</smiles>

Scheme 2. A detailed probable mechanistic interpretation for the oxidation of C.I. Acid Red 27 by CAT in acid medium. 


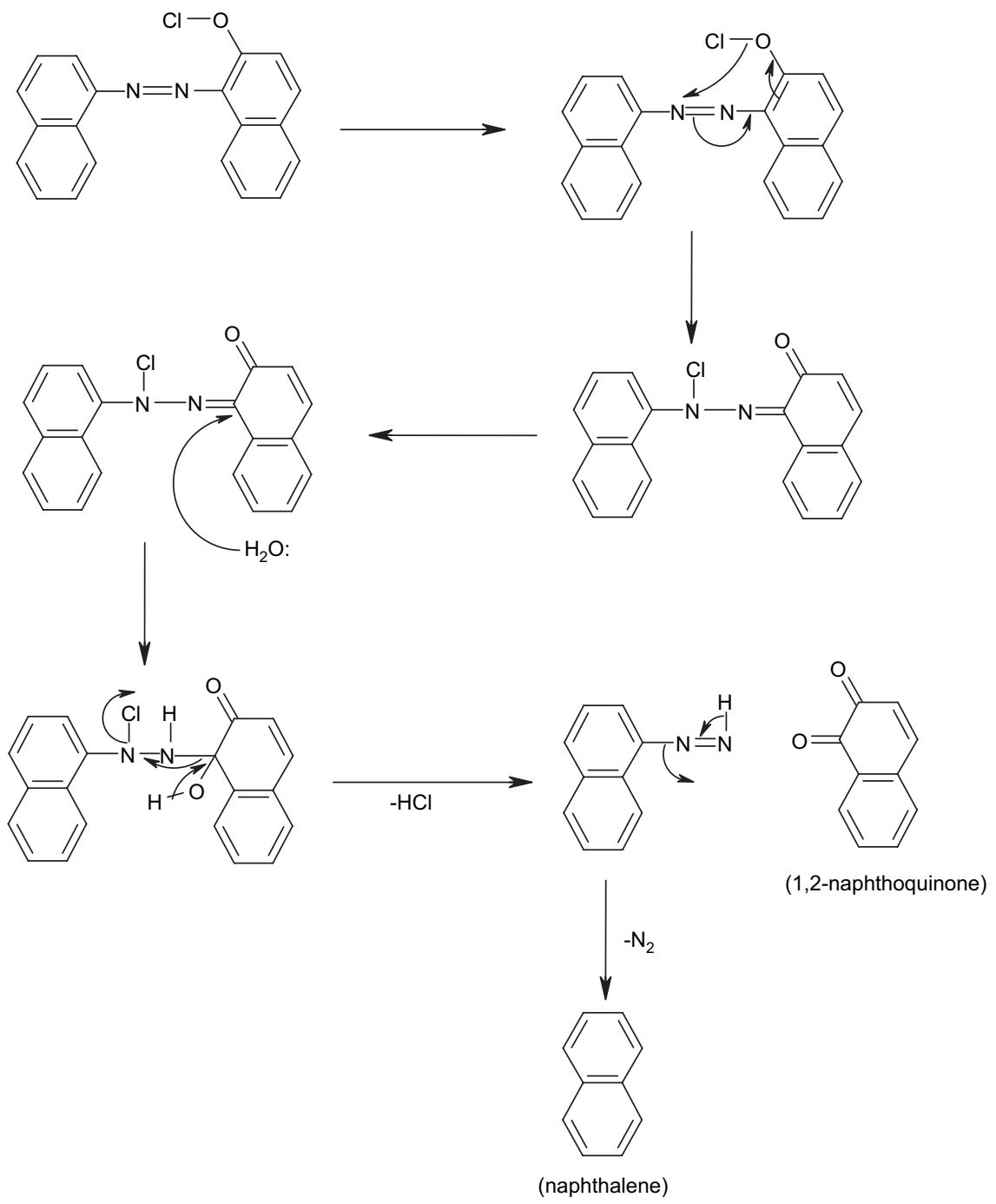

Scheme 2 (continued).

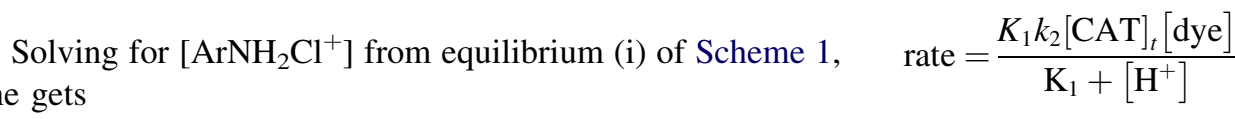

$\left[\mathrm{ArSO}_{2} \mathrm{NH}_{2} \mathrm{Cl}^{+}\right]=\frac{\left[\mathrm{ArSO}_{2} \mathrm{NHCl}\right]\left[\mathrm{H}^{+}\right]}{\mathrm{K}_{1}}$.

Upon substituting for $\left[\mathrm{ArNH}_{2} \mathrm{Cl}^{+}\right.$] from Eq. (11) into Eq. (10) and solving for $[\mathrm{ArNHCl}]$, one obtains:

$$
[\mathrm{ArNHCl}]=\frac{\mathrm{K}_{1}[\mathrm{CAT}]_{t}}{\mathrm{~K}_{1}+\left[\mathrm{H}^{+}\right]}
$$

From the slow step (ii) of Scheme 1,

rate $=\frac{-\mathrm{d}[\mathrm{CAT}]_{t}}{\mathrm{~d} t}=k_{2}[\mathrm{ArNHCl}][\mathrm{dye}]$

By substituting for [ArNHCl] from Eq. (12) into Eq. (13), the following rate law is obtained.
The proposed mechanism (Scheme 1) and the derived rate law (Eq. (14)) are in good agreement with the experimental results being a first-order dependence each on $[\mathrm{CAT}]_{0}$ and [dye $]_{0}$, and an inverse-fractional order on $\left[\mathrm{H}^{+}\right]$and also the observed stoichiometry of 1:1.

Since rate $=k^{\prime}[\mathrm{CAT}]_{t}$, Eq. (14) can be transformed into Eqs. (15) and (16):

$k^{\prime}=\frac{K_{1} k_{2}[\mathrm{dye}]}{K_{1}+\left[\mathrm{H}^{+}\right]}$

$\frac{1}{k^{\prime}}=\frac{1}{k_{2}[\text { dye }]}+\frac{\left[\mathrm{H}^{+}\right]}{K_{1} k_{2}[\text { dye }]}$

Based on the rate law (Eq. (16)), a plot of $1 / k^{\prime}$ versus $\left[\mathrm{H}^{+}\right]$ was found to be linear $(r=0.9921)$ and from the slope and intercept of the plot the values of equilibrium constant $\left(K_{1}\right)$ 
and the decomposition constant $\left(k_{2}\right)$ were found to be $6.05 \times 10^{-2} \mathrm{~mol} \mathrm{dm}{ }^{-3}$ and $8.69 \mathrm{dm}^{3} \mathrm{~mol}^{-1}$, respectively.

The mechanism (Scheme 1) and the rate law (Eq. (14)) are also supported by the following experimental facts:

For a reaction involving a fast pre-equilibrium $\mathrm{H}^{+}$or $\mathrm{OH}^{-}$ ion transfer, the rate increases in $\mathrm{D}_{2} \mathrm{O}$ medium since $\mathrm{D}_{3} \mathrm{O}^{+}$and $\mathrm{OD}^{-}$are a stronger acid and a stronger base $(\sim 2$ to 3 times greater), respectively, than $\mathrm{H}_{3} \mathrm{O}^{+}$and $\mathrm{OH}^{-}$ions [20,21]. The reverse holds good for the reactions involving retardation by $\mathrm{H}^{+}$or $\mathrm{OH}^{-}$ions. Hence, the proposed mechanism in the present case is supported by the decrease in rate in $\mathrm{D}_{2} \mathrm{O}$ medium, indicating retardation by $\left[\mathrm{H}^{+}\right]$. The magnitude, however, is small $\left(k^{\prime}\left(\mathrm{H}_{2} \mathrm{O}\right) / k^{\prime}\left(\mathrm{D}_{2} \mathrm{O}\right)=1.46\right)$ which can be attributed to the inverse-fractional-order dependence of rate on $\left[\mathrm{H}^{+}\right]$.

Many attempts have been made to explain quantitatively the effect of dielectric constant of the medium on the rates of the reaction in solutions. For the limiting case of zero angle of approach between two dipoles, Amis [22] has shown that a plot of $\log k_{\mathrm{D}}$ versus $1 / D$ is linear with a negative slope, i.e.,

$\log k_{D}=\log k_{\infty}-2 \mu_{1} \mu_{2} /\left(2.303 k_{\mathrm{B}} \operatorname{Tr}_{D}^{3}\right)$

where $k_{D}$ and $k_{\infty}$ are the rate constants in media of dielectric constant $D$ and $\infty$, respectively, $k_{\mathrm{B}}$ is the Boltzmann constant, $\mu_{1}$ and $\mu_{2}$ are the permanent moments on the dipoles, $r$ refers the distance of approach for the dipole, and $T$ is the absolute temperature. The present experimental observations, i.e., decrease in the rate with decrease in dielectric constant of the medium (by changing $\mathrm{MeOH}-\mathrm{H}_{2} \mathrm{O}$ composition), are in agreement with the interaction of molecular dipoles and the reaction pathways suggested to explain the kinetic results (Scheme 2).

The proposed mechanism is also supported by the moderate values of energy of activation and other thermodynamic parameters (Table 3). The lower energy of activation and high free energy of activation support the formation of highly solvated transition state. The large negative entropy of activation suggests the formation of the compact activated complex with fewer degrees of freedom. Further, the experimental observation shows that there is no effect of $p$-toluenesulfonamide, halide ions and ionic strength on the reaction rate which also substantiates the proposed mechanism.

In the present redox system the optimum conditions for the controlled oxidation of C.I. Acid Red 27 by CAT to naphthalene and 1,2-naphthoquinone were established in acid medium. These products are largely used in the syntheses of naphthalene analogues such as naphthols and naphthalene sulfonic acid, which are widely used in dyestuff industries. Consequently, this redox system can be scaled up to industrial operation. Furthermore, C.I. Acid Red 27 is one of the chief components in the effluents of various industries and is environmentally hazardous and also carcinogenic compound. Hence, the present simple method developed can be adopted for treating the C.I. Acid Red 27 dye present in industrial effluents to reduce the toxicity caused by this dye. Also, this method offers several advantages including short reaction times, ease of isolation of products, cost effective and relatively non-toxic reagents which make the reaction process simple, elegant and environmentally benign.

\section{Conclusions}

For the kinetics of oxidation of C.I. Acid Red 27 by Chloramine- $\mathrm{T}$ in perchloric acid medium, the experimental rate law is of the form: $-\mathrm{d}[\mathrm{CAT}] / \mathrm{dt}=k[\mathrm{CAT}]_{0}[\mathrm{dye}]_{0}\left[\mathrm{HClO}_{4}\right]^{-0.58}$. Naphthalene and 1,2-naphthoquinone were identified as oxidation products of C.I. Acid Red 27 by GC-MS analysis. Activation parameters and the reaction constants were evaluated. The observed results have been explained by a plausible mechanism and the related rate law has been deduced. The present redox system developed can be adopted for treating the C.I. Acid Red 27 dye present in industrial effluents to reduce the toxicity caused by this dye

\section{Acknowledgement}

One of the authors (K.N.V) is grateful to the Bangalore University, Bangalore for awarding the Research Fellowship under Interdisciplinary Collaborative Research Project. We thank Prof. B. S. Sheshadri and Prof. M. A. Pasha for helpful discussions.

\section{References}

[1] Zollinger H. Colour chemistry: syntheses, properties and applications of organic dyes and pigments. New York: VCH; 1981.

[2] Oakes J, Gratton P. Kinetic investigations of the oxidation of arylazonaphthol dyes in hypochlorite solutions as a function of $\mathrm{pH}$. J Chem Soc Perkin Trans 2 1998:2201. and reference therein.

[3] Zhang R, Zhang C, Cheng X, Wang L, Wu Y, Guan Z. Kinetics of decolorization of azo dye by bipolar pulsed barrier discharge in a three-phase discharge plasma reactor. J Hazard Mater 2007;142:105.

[4] Campbell MM, Johnson G. Chloramine-T and related $N$-halogeno- $N$ metallo reagents. Chem Rev 1978;78:65.

[5] Banerji KK, Jayaram B, Mahadevappa DS. Mechanistic aspects of oxidation by $N$-metallo- $N$-haloarylsulfonamides. J Sci Ind Res 1987;46:65.

[6] Puttaswamy, Anuradha TM, Ramachandrappa R, Gowda NMM. Oxidation of isoniazide by $N$-haloarenesulfonamides in alkaline medium: a kinetic and mechanistic study. Int J Chem Kinet 2000;32:221.

[7] Armesto XL, Canle L, Garia MV, Santaballa JA. Aqueous chemistry of $N$-halo-compounds. Chem Soc Rev 1998;27:453.

[8] Chrzaszczewska A. Chemistry of N-chloramides, III. Bull Soc Sci Lett Lodz Cl 1952;3:5;

Chem Abstr 1955;49:212.

[9] Ramachandra H, Rangappa KS, Mahadevappa DS, Gowda NMM. Oxidation of substituted phenethyl alcohols by sodium- $N$-chloro- $p$-toluene sulfonamide: a kinetic study. Monatsh Chem 1996;127:241.

[10] Puttaswamy, Jagadeesh RV. Kinetics of oxidation of pantothenic acid by chloramine- $\mathrm{T}$ in perchloric acid and in alkaline medium catalyzed by $\mathrm{OsO}_{4}$ : a mechanistic approach. Int J Chem Kinet 2005;37:201.

[11] Puttaswamy, Jagadeesh RV. Ruthenium (III)-catalyzed mechanistic investigation of oxidation of an azo dye by sodium $N$-haloarenesulfonamidates in acid medium: a comparative spectrophotometric kinetic study. Appl Catal A Gen 2005;292:259.

[12] Morris JC, Salazar JA, Wineman MA. Equilibrium studies on chloro compounds: the ionization constant of $N$-chloro- $p$-toluene sulfonamide. J Am Chem Soc 1948;70:2036.

[13] Puttaswamy, Mahadevappa DS, Rangappa KS. Oxidation of indigo carmine by $N$-haloarenesulfonamides: a kinetic study. Bull Chem Soc Jpn 1989;62:3343. 
[14] Akerloff G. Dielectric constants of some organic solvents-water mixtures at various temperatures. J Am Chem Soc 1932;54:4125.

[15] Bishop E, Jennings VJ. Titrimetric analysis with cholramine-T: the status of chloramine-T as a titrimetric reagent. Talanta 1958;32:1082.

[16] Hardy FF, Johnston JP. The interactions of $N$-bromo- $N$-sodiobenzesulfonamide (bromamine-B) with $p$-nitro phenoxide ion. J Chem Soc Perkin Trans 1 1973;2:742.

[17] Pryde BG, Soper FD. The interactions of anilides and hypochlorous acid. J Chem Soc 1926:1510.
[18] Narayanan SS, Rao VRS. Chlorine isotopic exchange reaction between chloramine-T and chloride ions. Radiochim Acta 1981;49:193.

[19] Subhashini M, Subramani M, Rao VRS. Determination of the protonated constant of chloramine-B. Talanta 1985;32:1082.

[20] Collins CJ, Bowman NS. Isotope effect in chemical reactions. New York: Van Nostrand Reinhold; 1970.

[21] Wiberg KB. The deuterium isotope effect. Chem Rev 1955;55:713.

[22] Amis ES. Solvent effects on reaction rates and reaction mechanisms. New York: Academic; 1966. 